\title{
The Impact of Misuse and Diversion of Opioid Substitution Treatment Medicines: Evidence Review and Expert Consensus
}

\author{
Jens Reimer $^{\mathrm{a}} \quad$ Nat Wright $^{\mathrm{b}} \quad$ Lorenzo Somaini $^{\mathrm{c}} \quad$ Carlos Roncero $^{\mathrm{d}}$ \\ Icro Maremmani ${ }^{\mathrm{e}}$ Neil McKeganey ${ }^{f}$ Richard Littlewood ${ }^{g}$ Peter Krajci $^{\text {h }}$ \\ Hannu Alho' Oscar D'Agnone ${ }^{\mathrm{j}}$ \\ ${ }^{a}$ Centre for Interdisciplinary Addiction Research, University Medical Centre Hamburg-Eppendorf, Hamburg,

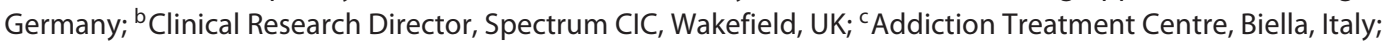 \\ ${ }^{\mathrm{d}}$ Addiction and Dual Diagnosis Unit, Department of Psychiatry, Vall d'Hebron Hospital - Public Health Agency,

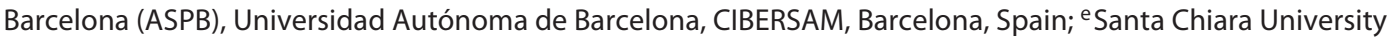 \\ Hospital, University of Pisa, Pisa, Italy; ${ }^{\mathrm{f} C e n t r e ~ f o r ~ D r u g ~ M i s u s e ~ R e s e a r c h, ~ G l a s g o w, ~ U K ; ~}{ }^{9}$ Applied strategic, London, \\ UK; ${ }^{\mathrm{h}}$ Division of Mental Health and Addiction, Department of Substance Use Disorder Treatment, Oslo University \\ Hospital, Oslo, Norway; 'University of Helsinki, Helsinki, Finland; ${ }^{j}$ Honorary Professor of the Faculty of Medical and \\ Human Sciences, Institute of Brain Behaviour and Mental Health, University of Manchester, Manchester, UK
}

\section{Key Words}

Misuse - Diversion · Buprenorphine $\cdot$ Methadone $\cdot$ Opioid substitution treatment

\begin{abstract}
Background/Aims: Opioid substitution treatment (OST) improves outcomes in opioid dependence. However, controlled drugs used in treatment may be misused or diverted, resulting in negative treatment outcomes. This review defines a framework to assess the impact of misuse and diversion. Methods: A systematic review of published studies of misuse and diversion of OST medicines was completed; this evidence was paired with expert real-world experience to better understand the impact of misuse and diversion on the individual and on society. Results: Direct impact to the individual includes failure to progress in recovery and negative effects on health (overdose, health risks associated with injecting behaviour). Diversion of OST has impacts on a community that is beyond the intended OST recipient. The direct
\end{abstract}

\section{KARGER}

E-Mail karger@karger.com www.karger.com/ear impact includes risk to others (unsupervised use; unintended exposure of children to diverted medication) and drugrelated criminal behavior. The indirect impact includes the economic costs of untreated opioid dependence, crime and loss of productivity. Conclusion: While treatment for opioid dependence is essential and must be supported, it is vital to reduce misuse and diversion while ensuring the best possible care. Understanding the impact of OST misuse and diversion is key to defining strategies to address these issues.

(c) 2015 S. Karger AG, Basel

\section{Introduction}

Opioid dependence is a problem that exacts a significant toll on public health and generates criminal, health and economic costs quantifiable in the billions. The United Nations Office on Drugs and Crime estimates that there are between 16 and 39 million problem drug users worldwide [1]. 
Effective interventions for opioid dependence are available. The best treatment outcomes are achieved when a comprehensive multidisciplinary approach such as opioid substitution treatment (OST) is offered, including opioid-substitution medicines and integrated health and social care interventions to respond to individual patient needs [2]. The current term OST has limitations because it does not describe the nature of the medications involved, which do not necessarily have substitutive effects for illicit opioids, but reduce cravings and control addictive behaviour [3]. Better terms that can be used in the future might include prescription-only opioid treatment or long-acting opioid treatment, but for our study now, the term OST is used for clarity.

OST has been successful in reducing the harm associated with opioid dependence (overdose deaths, crime) and limiting the spread of blood-borne viruses (BBV) [4]. However, due to the agonist nature of OST medication, it can be diverted or misused for recreational, self-medication or other purposes. Diversion is defined as the intentional transfer of a controlled drug from legitimate distribution and dispensing into illegal channels [5]. Misuse is defined as the use of a medication other than as directed or as indicated, whether willful or unintentional, and whether it results in harm or not [6]. Assessment of the impacts of OST medication misuse and diversion exists in various publications, but there are no complete descriptions of the far-reaching extent of these impacts. Currently, no systemised approach to describe the impacts of misuse and diversion exists. Here, a framework to assess outcomes in opioid dependence treatment [7] has been used to describe the problem and its direct and indirect consequences to the individual and society.

Experts in the field used a systematic review to populate this framework, aiming to better define and understand the impact of misuse and diversion on outcomes in care as a starting point to inform change in the delivery of opioid dependence care. They noted that misuse and diversion reduce the probability of successful outcomes from the treatment of opioid dependence. Defining the impact of misuse and diversion can help build a consensus regarding the best response to reduce the problem and improve care.

\section{Method}

A literature search was performed on PubMed and Google, covering the period from January 1993 to June 2014, to identify publications reporting diversion or misuse of buprenorphine- and methadone-containing medications. The search terms used were: 'buprenorphine' or 'methadone' and 'misuse' or 'diversion', in the title or abstract. Two independent reviews of the initial literature search results were conducted, classifying publications based on relevance to this study and those that fit within the defined framework. Papers were considered relevant if they contained original qualitative or quantitative research pertaining to misuse or diversion (as defined in the Introduction) of buprenorphine- or methadone-containing opioid substitution medicines. Reviews and commentaries/editorials were excluded. These 2 rounds of review identified key sources of evidence in the published literature. In addition to the systematic literature review, experts provided clinical experience from day-to-day practice managing the care of people with opioid dependence.

A meeting of experts in the field was convened to discuss identified literature and experience working in the field. This meeting, which was aimed at creating a consensus on the interpretation and analysis of findings from different sources describing the extent and impact of misuse and diversion of OST medication, was held in 2014.

\section{Results}

Of the total 645 results from the literature search, the review identified 44 sources describing the impact of misuse and diversion of OST medication (table 1). This review includes only sources containing strong empirical data informing the discussion, and the results that fit into a framework (fig. 1), defining impacts of misuse and diversion as direct or indirect and on the individual (25 articles) or on society (19 articles).

\section{Individual}

Non-adherence to guidance for OST medication includes injection or snorting of oral medicines and diverted use by a person for whom it is not prescribed [8]. Noncompliance with treatment often leads to poor treatment outcomes and eventual dropout. Medication diversion impacts the benefit patients experience from treatment by limiting adherence through the sale of medication, prolonging contact with active drug users and maintaining participation in a drug-use lifestyle $[9,10]$. One analysis suggests a correlation between daily-dose buprenorphine and positive outcomes, where the treatment dropout rate and non-compliance are greater if a patient is undertreated with buprenorphine [11], while a UK case study indicates that treatment compliance is increased and misuse decreased when patients were involved in setting goals for treatment [10].

For the 10 million injecting drug users (IDUs) worldwide [2] who may share injecting paraphernalia [12], the risks of injecting include contracting and spreading BBV and other infections, and the frequency of infection may 
Table 1. Key results of extended review of literature

\begin{tabular}{|c|c|c|c|c|}
\hline Author & Year & Country & Method & Evidence of impact on \\
\hline $\begin{array}{l}\text { Health } \\
\text { Degenhardt } \\
\text { et al. [8] }\end{array}$ & 2009 & Australia & $\begin{array}{l}\text { Injecting was studied in regular } \\
\text { IDUs and current OST clients. } \\
\text { Regular IDUs were interviewed } \\
\text { annually and data for } 2003-2007 \\
\text { were compiled; } 399 \text { clients were } \\
\text { interviewed in } 2007 \text {. }\end{array}$ & $\begin{array}{l}\text { Both misuse and diversion of pharmaceutical opioids } \\
\text { (including those prescribed for pain management) cause } \\
\text { significant public health problems in many countries. There is } \\
\text { suggestive evidence that supervised dosing may reduce } \\
\text { diversion, and restricted access to syringes facilitating injection } \\
\text { of large volumes may reduce injecting. }\end{array}$ \\
\hline $\begin{array}{l}\text { Farrell } \\
\text { et al. [21] }\end{array}$ & 2008 & UK & $\begin{array}{l}\text { National sample of } 48,771 \text { male } \\
\text { and female sentenced prisoners } \\
\text { released during } 1998-2000 \text { with } \\
\text { all recorded deaths included to } \\
\text { November } 2003 \text {. }\end{array}$ & $\begin{array}{l}\text { There were } 442 \text { recorded deaths from a sample of } 48,771 \\
\text { prisoners, of which } 261 \text { ( } 59 \%) \text { were drug-related. In the year } \\
\text { following release, the drug-related mortality rate was } 5.2 \text { per } \\
1,000 \text { among men and } 5.9 \text { per } 1,000 \text { among women. Opioids } \\
\text { were involved in } 95 \% \text { of deaths and methadone was involved in } \\
14 \% \text { of deaths. }\end{array}$ \\
\hline $\begin{array}{l}\text { Jenkinson } \\
\text { et al. [15] }\end{array}$ & 2005 & Australia & $\begin{array}{l}156 \text { current injecting drug users } \\
\text { in } 5 \text { Needle and Syringe } \\
\text { programme sites in Melbourne, } \\
\text { Australia. }\end{array}$ & $\begin{array}{l}37 \% \text { of IDUs surveyed reported ever injecting BPN, and } 33 \% \\
\text { had injected BPN in the past } 6 \text { months. } 47 \% \text { of those who } \\
\text { reported recent BPN injection obtained the drug illicitly at least } \\
\text { once. Of the } 83 \text { people who reported use of BPN in the last } \\
6 \text { months, } 37 \% \text { reported obtaining the drug illicitly at least } \\
\text { once during that period, and } 26 \% \text { reported mostly using illicitly } \\
\text { obtained BPN. }\end{array}$ \\
\hline
\end{tabular}

\section{Harm}

House of 2012 UK Annual report of HM Chief

Commons Inspector of Prisons.

[29]

Annual report of HM Chief

(n)
Diverted medication was reported in a majority of prisons inspected, resulting in problems such as drug debts, bullying, unknown interactions with other prescribed drugs and the risk of overdose. BPN and cannabis were found more frequently than heroin.

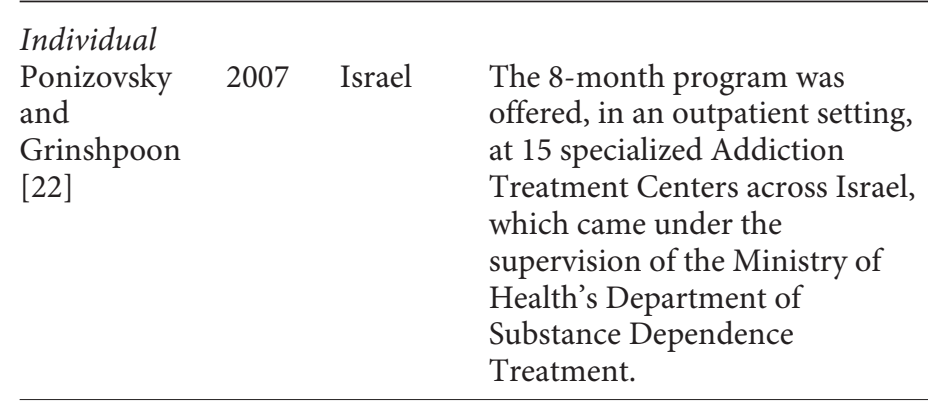

Donmall 2009 UK The DTORS study comprised a
et al. [23] longitudinal survey of treatment outcomes, a qualitative assessment of the factors that impact effective treatment, and an economic analysis.
QoL is severely impaired in opioid-dependent addicts.

Treatment including either MET and BPN have beneficial effects on satisfaction with QoL and all specific life domains in heroin-dependent outpatients; however, OST misuse may lead to severe health problems and negate the benefits of treatment.
Use of heroin and other opioids, and misuse of unprescribed methadone, decreased significantly among 1,796 people from entry to treatment through 11-13 months. An economic analysis estimated a net saving of $£ 6,500$ per person for drug treatment, compared to no treatment. There was a net gain in health as measured by QALYs. The results suggest that drug treatment has $\sim 80 \%$ chance of being cost-effective for each individual. 
Table 1. (continued)

\begin{tabular}{|c|c|c|c|c|}
\hline Author & Year & Country & Method & Evidence of impact on \\
\hline $\begin{array}{l}\text { Policy } \\
\text { Review [9] }\end{array}$ & 2014 & UK & $\begin{array}{l}\text { Discussion on integrated policy } \\
\text { responses to misuse of } \\
\text { prescribed medicines in } \\
\text { Europe. }\end{array}$ & $\begin{array}{l}\text { Medication diversion impacts the benefit patients experience } \\
\text { from treatment by limiting adherence through the sale of their } \\
\text { medication, prolonging contact with active drug users and } \\
\text { maintaining their participation in a drug-use lifestyle. Where } \\
\text { diversion and misuse occur in a treatment setting, this can } \\
\text { impact a doctor's own practice and there may even be legal } \\
\text { complications. There are cases where doctors have been } \\
\text { imprisoned when diverted medications implicated in fatalities } \\
\text { have been tracked back to negligent clinical practice. }\end{array}$ \\
\hline
\end{tabular}

\section{Society}

World Health $2009 \quad$ - $\quad$ Guidance for psychologically Organization assisted opioid-dependence [26] assisted op

Unsupervised administration of OST medication results in increased rates of misuse and diversion to illicit drug markets. Children and opioid-naive adults may consume take-home doses. Restrictions may be necessary to prevent diversion and misuse.

Adfam [27] $2014 \quad$ UK $\quad$ This report examines cases where children have died or come to harm from OST medicines prescribed to help people overcome drug addiction.
In 2011-2012, it was recorded that 60,596 adults in treatment had parental responsibility, an opiate problem, and were receiving a prescribing intervention. In 2003, it was estimated that 250,000-350,000 children in the United Kingdom were affected by parental drug use; in 2009, a reported 120,000 children were living with a parent currently engaged in treatment. There were 17 fatalities and 6 non-fatal ingestions of OST medications by children during this period, not accounting for the number of 'near misses' or incidents that failed to culminate in a report. 18 cases involved methadone and 1 involved buprenorphine. 3 cases involved intentional misuse of methadone by teenagers.

$60 \%$ of those taking BPN obtained it from doctors, $40 \%$ obtained it from 'friends' or the black market. 53.3\% of subjects started intravenous drug use only after the introduction of BPN.

\begin{tabular}{lrl}
\hline $\begin{array}{l}\text { Noroozi and } \\
\text { Mianji [39] }\end{array}$ & $\begin{array}{r}\text { Singapore } \\
\text { Study assessed } 120 \\
\text { buprenorphine abusers for } \\
\text { quality of life ratings. }\end{array}$
\end{tabular}

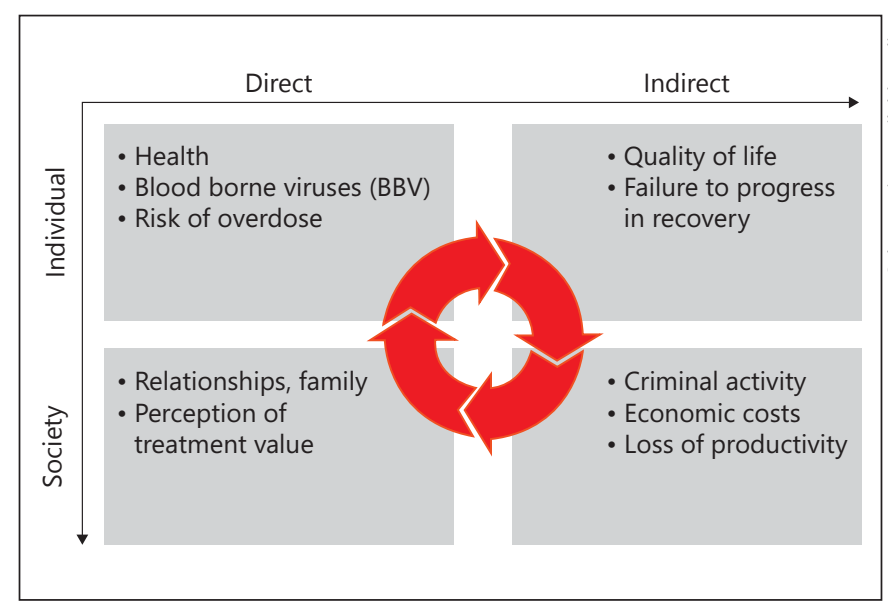

Fig. 1. Framework defining terms of direct and indirect outcomes of misuse and diversion of OST medication. be on the increase $[13,14]$. OST medicines are known to be injected: for instance, 37\% of 156 IDUs surveyed in Melbourne in 2002 reported ever having injected monobuprenorphine [15]. There is no available data specifically reporting the risks of misuse of OST medicines by injection, but it is reasonable to assume that the risks of disease spreading via injecting drug use are similar regardless of the substance injected.

Drug overdose presents another significant impact of misuse and diversion. Fatalities due to methadone overdose are a major concern in OST administration: deaths in which methadone was the sole reported drug totalled 258 in Scotland and 2,343 in England over the period 1993-2008 [16]. The number of drug-related deaths where methadone alone is mentioned on the death certificate in England and Wales rose from 201 in 2003 to 
429 in 2013. It is not known what proportion of these deaths is related to methadone, which has been diverted; considering the frequency of OST diversion, it is possible that many of these deaths may be related to methadone diversion [17]. The role of diversion in overdose fatalities has been described in some studies: $51 \%$ of methadone overdose fatalities in Hamburg in 2007-2012 were people not in OST treatment at the time of death [18]. A study in North Carolina in 2010 reported that unintentional or undetermined drug overdoses were responsible for 892 deaths: out of the 191 deaths examined involving methadone, only 2 were patients in opioid treatment programs [19]. According to another study of 312 individuals who had died after taking methadone over the period 20002006 in Norway, in $85 \%$ of cases $(n=264)$, the deceased had died of methadone-related intoxication, most often in combination with benzodiazepines, cannabis and other opioids. Of those deceased due to methadone related intoxication, $78 \%$ had used diverted methadone [20]. OST medicines may be diverted within prisons, and a study by Farrell and Marsden [21] showed that more than half of the 442 deaths that occurred in a cohort of 48,771 UK prisoners were due to drug-related overdose. This finding led to the introduction of structured Integrated Drug Treatment System programmes in UK prisons to address drug diversion, misuse and overdose.

The indirect impact of misuse and diversion on the individual includes a decreased quality of life (QoL). QoL is severely impaired in opioid-dependent addicts, but few studies have been conducted comparing different substitution agents with respect to QoL outcomes [22]. QoL of those misusing their OST medication can be presumed to be similar to normal drug users; successful treatment increases QoL [23].

Misuse and diversion may be associated with mental health problems: in the United States, a review of public databases found that $3 \%$ of adults older than 50 years receiving outpatient psychiatric treatment used illicit drugs, and that drug users in methadone maintenance treatment exhibited multiple psychiatric or medical conditions [24]. A majority of mental health professionals perceive non-compliance in patients diagnosed with both a mental illness and a substance addiction (dual diagnosis). The reasons for the nonadherence to treatment are poor disease awareness, side effects, low efficacy and complicated posology [25].

Some studies suggest that using the combination of buprenorphine/naloxone may reduce misuse and diversion: 18 months after introduction of the buprenorphine/ naloxone combination in Australia, 9\% of regular IDUs reported injecting the combination product in the past

The Impact of Misuse and Diversion of OST Medicines
6 months compared to 23\% for buprenorphine and $17 \%$ for methadone $(n=513)$. In a group of 399 subjects in OST, $10 \%$ receiving the combination product $(n=116)$ had injected within the past 6 months compared with $30 \%$ receiving buprenorphine $(n=126)$ and $24 \%$ receiving methadone $(n=157)$ [8].

\section{Society}

Misuse and diversion of OST medicines can directly impact relationships with family and friends, sometimes placing children of misusing parents in danger of accidental exposure. Reports show that diverted medication is occasionally consumed by children and opioid-naive adults with fatal consequences [26]. In 2011-2012, it was recorded that 60,596 adults in treatment in the United Kingdom had parental responsibility, an opioid problem, and were receiving OST medicine. 17 fatalities and 6 non-fatal ingestions of OST medications by children were recorded in the same study in the 10-year period between 2004 and 2014 [27]. A retrospective review identified 22 paediatric admissions in the United States over 10 years for accidental methadone or buprenorphine ingestion and reported that there were $10(46 \%)$ children admitted for methadone and 12 (54\%) admitted for buprenorphine ingestion, with ingestions tripling in the last 5 years of the study. The trend was statistically significant and correlated with the number of patients in OST in the region [28]. It has been reported that fatalities in children are in some cases attributable to diverted medicines. In the United Kingdom, case reviews reported that 23 children were involved in serious overdoses in 2004-2014, 17 of which resulted in fatalities. A great majority of these cases involved methadone, while a few involved buprenorphine. In some of these cases, exposure to OST medication was thought to be deliberate misuse of methadone by teenagers [27].

Misuse and diversion cause indirect harm to society via criminal activity, economic costs and loss of productivity. Criminality and contact with the black market are implied when medication is diverted with economic motivations, or when medication is purchased for misuse. Diverted medication is reported in the majority of prisons inspected in the United Kingdom, resulting in problems such as drug debts, bullying, unknown interactions with other prescribed drugs and risk of overdose [29].

The cost of untreated opioid dependence is measured in the millions [30-33]. It is difficult to estimate the exact costs of misuse and diversion; however, it is reasonable to assume that some costs corresponding to drug use and treatment may be indicative of the actual costs of OST medicine misuse and diversion. In 2006, the estimated 
total cost of misuse of prescription opioids in the United States was $\$ 53$ billion, of which $\$ 42$ billion (79\%) was attributable to lost productivity, $\$ 8$ billion (15\%) to criminal justice costs, $\$ 2$ billion (4\%) to drug abuse treatment, and $\$ 944$ (2\%) million to medical complications [34].

Misuse and diversion may prevent recovery from drug addiction, which benefits public health and cuts crime as well as delivering value for money for the taxpayer. For instance, in the United Kingdom, it is estimated that every $£ 1$ spent on treatment delivered $£ 2.50-£ 3.50$ benefit to society, chiefly by cutting crime and also by reducing health and social costs $[32,35]$. Other data showed that drug treatment and recovery systems in England may have prevented approximately 5 million crimes in 20102011 , with an estimated savings of $£ 960$ million in costs to the public, businesses, the criminal justice system and the National Health Service [36]. A Public Health England report analyzing costs and savings of opioid dependence treatment to public services states that residential treatment pathways cost approximately $£ 25,000$ per patient over 3 years - about 5 times the average cost of community pathways, which are estimated to total approximately $£ 6,000$ per patient. This report also estimates the loss of productivity costs depending on the complexity level of the patient that can range from $£ 5,000$ to $£ 9,000$ for residential treatment patients and from $£ 2,000$ to $£ 3,000$ for community patients. Estimated net health and social care savings for 100 clients with very high complexity levels on a community pathway are approximately $£ 22,000$ more than for 100 clients with very high complexity levels on a residential pathway [37]. In Italy, a study estimated that every $€ 1$ spent in outpatient OST saves $€ 6$ [38]. Importantly, savings to society will not justify the costs of treatment if misuse or diversion prevents positive treatment outcomes such as recovery from addiction, improved health, and desistance from crime. Diversion and misuse may also present a threat to the reputation of OST services, which could compromise public acceptance of treatment for opioid-dependent individuals and access to treatment [39].

\section{Discussion}

The intensity of the problems associated with opioid dependence has been described: mortality rates of over 40 drug-related deaths per million were reported in $6 \mathrm{EU}$ countries, with the highest rates in Norway (76 per million) and Estonia (191 per million) [40]. More than 30,000 deaths from unintentional drug overdose were reported in the United States in 2010; drug overdose death rates have been rising steadily since 1992 with a $102 \%$ increase from 1999 to 2010 alone [41].

The effectiveness of well-delivered, evidence-based treatment for drug use is well established [12]. International studies consistently show that drug treatment covering different types of drug problems, using different treatment interventions and in different treatment settings - impacts positively the levels of drug use, offending, overdose risk and the spread of BBV. However, misuse and diversion may reduce the efficacy of treatment. Reported rates of selling, giving away or swapping OST medicine vary from $16 \%$ in Portugal, where $21 \%$ of dosing is supervised, to $16 \%$ in Greece, where $78 \%$ of dosing is supervised, to $39 \%$ in France where $26 \%$ of dosing is supervised [42]. A UK survey of 886 OST patients found that $60 \%$ of patients on supervised methadone dosing would prefer not to be reasons of the stigma associated with methadone [10]. Understanding factors, including supervision and the proportion of methadone and buprenorphine prescription, that contribute to misuse and diversion is important to delivering effective care for opioid dependence.

There is a lack of documented evidence of the quantitative impact of misuse and diversion, especially with regards to the QoL of those misusing OST medication. The results of this literature review, interpreted within the framework of real-world experience of experts in the field, define a consensus expert opinion that the misuse and diversion of OST medication negatively impact treatment outcomes and the community as a whole. First, an increase in mortality rates compared to the general population is evident. Individuals are also put at risk of BBV through the practice of injecting drug use $[43,44]$. Misuse and diversion increase stigma and result in poor adherence to recommended treatment [39]. Beyond the individual, many children are put at significant risk, including that of accidental ingestion, by parents misusing OST medication [27]. With a rise in demand for diverted OST medications comes an increase in associated crime. Diversion as thefts from pharmacies and from homeowners reflects demand for illicit OST medications. A common form of diversion is 'doctor shopping', which occurs when a person seeks care from multiple medical practitioners at the same time for the purpose of obtaining medications from more than one prescriber. This increase in crime contributes to significant costs to society, which also includes expenditure associated with medical treatment of overdose, complications, and associated illnesses such as BBV. This economic impact of misuse and 
diversion of OST medication is documented in the published literature.

Experts agree that all of these harms make misuse and diversion problems something that needs to be addressed; further research specific to misuse and diversion is required to better understand the drivers and define strategies that effectively reduce misuse and diversion. Establishing Europe-wide prevalence data pertaining to misuse and diversion using a standardised tool for data collection would enable the identification of possible confounders (e.g. differences in prescribing regimes; differences in mean duration of supervised dispensing; differences in criminal record rates). This standardised prevalence data could allow the determination of factors affecting misuse and diversion and identification of a typology of drug users who could be suitable for supervised dispensing and those who could be suitable for take-home doses. The uncertainties in assessing and responding to diversion and misuse may be a factor deterring physician participation in OST; however, experts note that prescribing more abuse-deterrent forms of medication could serve as one intervention among others within the OST system to potentially increase quality, acceptance and access to treatment [45], as the policy and legal framework concerning opioid addiction treatment is continually under debate $[46,47]$.

\section{Conclusion}

Misuse and diversion of OST medication are serious problems in health, social and economic terms. It is evident that diversion leads to criminal behaviour and poor treatment outcomes due to non-adherence, while the impacts of misuse range from poor health to increased rates of mortality and the spread of BBV. There are many useful guidelines for the management of opioid dependence. While it is clear from individual sources of evidence that the impact of misuse and diversion of OST includes a broad range of negative outcomes for the individual and for society, there is no clear definition in quantitative terms to support a significant change in treatment delivery and opioid dependence care.

Further work to define the impact of misuse and diversion of OST medication more precisely is recommended; this evidence will be critical for defining strategies to reduce misuse and diversion and improve outcomes in OST-based opioid dependence management. Addressing these problems will ultimately support positive outcomes for public health.

\section{Acknowledgements}

Asta Kurulyte and Jenna Riffell provided support in the preparation of manuscript.

\section{Role of the Funding Source}

The authors gratefully acknowledge financial support from RB Pharmaceuticals in support of the Misuse and Diversion meeting and in support of professional editorial assistance for the production of this manuscript. The manuscript represents the work of the authors with editorial assistance from applied strategic. RB Pharmaceuticals have not reviewed the manuscript or had any other influence on its content.

\section{Contributors}

All authors were involved in the study design, had full access to the survey data and analyses, and interpreted the data, critically reviewed the manuscript and had full control, including final responsibility for the decision to submit the paper for publication.

\section{Disclosure Statement}

All authors have no conflict of interest.

\section{References}

1 United Nations Office on Drugs and Crime: World Drug Report 2014, 2014.

2 World Health Organization: Principles of Drug Dependence Treatment. Discussion Paper, 2008.

3 Gerra G, Maremmani I, Capovani B, Somaini L, Berterame S, Tomas-Rossello J, et al: Longacting opioid-agonists in the treatment of heroin addiction: why should we call them 'substitution'? Subst Use Misuse 2009;44:663-671.
4 Bell J: Medications in Recovery: Re-Orientating Drug Dependence Treatment. Appendix C - Opioid Substitution Treatment and Its Effectiveness: Review of the Evidence, 2012.

5 Smith SM, Dart RC, Katz NP, Paillard F, Adams EH, Comer SD, et al: Classification and definition of misuse, abuse, and related events in clinical trials: ACTTION systematic review and recommendations. Pain 2013;154:22872296.
6 Katz NP, Birnbaum H, Brennan MJ, Freedman JD, Gilmore GP, Jay D, et al: Prescription opioid abuse: challenges and opportunities for payers. Am J Manag Care 2013;19:295302 .

7 Maremmani I, Hill D, Gilman M, Littlewood $\mathrm{R}$ : Increasing importance of measuring outcomes in opioid dependence care: what matters now and in the future? Heroin Addict Relat Clin Probl 2014:5-12. 
8 Degenhardt L, Larance BK, Bell JR, Winstock $A R$, Lintzeris N, Ali RL, et al: Injection of medications used in opioid substitution treatment in Australia after the introduction of a mixed partial agonist-antagonist formulation. Med J Aust 2009;191:161-165.

9 National Drug Coordinators' Meeting: Misuse and Diversion of Opioid Substitution Treatment (OST). Policy Rev 2014. http:// docs.cgsltd.eu/misuse/policy-review/files/ assets/basic-html/page42.html.

10 Duffy P, Baldwin H: The nature of methadone diversion in England: a Merseyside case study. Harm Reduct J 2012;9:3.

11 Dhawan A, Chopra A: Does buprenorphine maintenance improve the quality of life of opioid users? Indian J Med Res 2013;137:130135.

12 Department of Health (England): Drug Misuse and Dependence: UK Guidelines on Clinical Management. London, 2007.

13 National Institute for Health and Clinical Excellence: Needle and Syringe Programmes: Providing People Who Inject Drugs With Injecting Equipment. NICE Public Health Guidance 18, 2009.

14 Poloméni P, Schwan R: Management of opioid addiction with buprenorphine: French history and current management. Int J Gen Med 2014;7:143-148.

15 Jenkinson RA, Clark NC, Fry CL, Dobbin M: Buprenorphine diversion and injection in Melbourne, Australia: an emerging issue? Addiction 2005;100:197-205.

16 Strang J, Hall W, Hickman M, Bird SM: Impact of supervision of methadone consumption on deaths related to methadone overdose (1993-2008): analyses using OD4 index in England and Scotland. BMJ 2010;341:c4851.

17 Office for National Statistics: Number of Drug-Related Deaths Where Selected Substances Were Mentioned on the Death Certificate, England and Wales, Deaths Registered Between 1993-2013, 2014

18 Iwersen-Bergmann S, Jungen H, AndresenStreichert H, Müller A, Elakkary S, Püschel K, et al: Intravenous methadone application as a serious risk factor for an overdose death: methadone-related fatalities in Hamburg from 2007 to 2012. Int J Legal Med 2014;128: 751-764.

19 Hirsch A, Proescholdbell SK, Bronson W, Dasgupta N: Prescription histories and dose strengths associated with overdose deaths. Pain Med 2014;15:1187-1195.
20 Bernard J-P, Havnes I, Slørdal L, Waal H, Mørland J, Khiabani HZ: Methadone-related deaths in Norway. Forensic Sci Int 2013 Jan 10;224:111-6.

21 Farrell M, Marsden J: Acute risk of drug-related death among newly released prisoners in England and Wales. Addiction 2008; 103:251255.

22 Ponizovsky AM, Grinshpoon A: Quality of life among heroin users on buprenorphine versus methadone maintenance. Am J Drug Alcohol Abuse 2007;33:631-642.

23 Donmall M, Jones A, Davies L, Barnard M: Summary of Key Findings from the Drug Treatment Outcomes Research Study (DTORS), 2009.

24 Wu L-T, Blazer DG: Substance use disorders and psychiatric comorbidity in mid and later life: a review. Int J Epidemiol 2014;43:304-317.

25 Roncero C, Gómez-Baeza S, Vázquez JM, Terán A, Szerman N, Casas M, et al: Perception of Spanish professionals on therapeutic adherence of dual diagnosis patients. Actas Esp Psiquiatr 2013;41:319-329.

26 World Health Organization: Guidelines for the Psychosocially Assisted Pharmacological Treatment of Opioid Dependence, 2009.

27 Adfam: Medications in Drug Treatment: Tackling the Risks to Children, 2014.

28 Martin TC, Rocque M a: Accidental and nonaccidental ingestion of methadone and buprenorphine in childhood: a single center experience, 1999-2009. Curr Drug Saf 2011;6: $12-16$.

29 House of Commons: HM Chief Inspector of Prisons for England and Wales, 2012.

30 NIDA: DrugFacts: Treatment Statistics. Subst Abus Ment Heal Serv Adm 2011. http://www. drugabuse.gov/publications/drugfacts/treatment-statistics

31 Wall R, Rehm J, Fischer B, Brands B, Gliksman L, Stewart J, et al: Social costs of untreated opioid dependence. J Urban Health 2000; 77:688-722.

32 Gossop M, Marsden J, Stewart D, Kidd T: The National Treatment Outcome Research Study (NTORS): 4-5 year follow-up results. Addiction 2003;98:291-303.

33 Singleton N, Murray R, Tinsley L: Measuring Different Aspects of Problem Drug Use: Methodological Developments, 2006.

34 Hansen RN, Oster G, Edelsberg J, Woody GE, Sullivan SD: Economic costs of nonmedical use of prescription opioids. Clin J Pain 2011; 27:194-202.
35 Public Health England: Written Evidence from the National Treatment Agency for Substance Misuse (PH 04). 2011. http:// www.publications.parliament.uk/pa/cm 201012/cmselect/cmhealth/1048/1048we05. htm.

36 NTA for Substance Misuse: Estimating the Crime Reduction Benefits of Drug Treatment and Recovery, 2012.

37 Department for Work and Pensions, Public Health England: Understanding the Costs and Savings to Public Services of Different Treatment Pathways for Clients Dependent on Opiates, 2015.

38 Dipartimento per le politiche antidroga: Relazione annuale 2013. Pres del Cons dei Minist 2013. http://www.politicheantidroga. it/progetti-e-ricerca/relazioni-al-parlamento/ relazione-annuale-2013/presentazione.aspx.

39 Noroozi A, Mianji F: Singapore's experience with buprenorphine (subutex). IJPBS 2008;2: 54-59.

40 EMCDDA: European Drug Report 2014: Trends and Developments, 2014.

41 Centers for Disease Control and Prevention: Injury Prevention and Control: Prescription Drug Overdose. Centers Dis Control Prev 2014. http://www.cdc.gov/homeandre creationalsafety/overdose/facts.html.

42 Dale-Perera A, Goulão J, Stoever H: Quality of care provided to patients receiving opioid maintenance treatment in Europe: results from the EQUATOR survey. Heroin Addict Relat Clin Probl 2012;14:23-38.

43 Wang X, Zhang T, Ho WZ: Opioids and HIV/ HCV infection. J Neuroimmune Pharmacol 2011;6:477-489.

44 Nelson PK, Mathers BM, Cowie B, Hagan H, Des Jarlais D, Horyniak D, et al: Global epidemiology of hepatitis $B$ and hepatitis $C$ in people who inject drugs: results of systematic reviews. Lancet 2011;378:571-583.

45 Merrill JO: Policy progress for physician treatment of opiate addiction. J Gen Intern Med 2002;17:361-368.

46 Strang J, Babor T, Caulkins J, Fischer B, Foxcroft D, Humphreys K: Drug policy and the public good: evidence for effective interventions. Lancet 2012;379:71-83.

47 USAID Health Policy Initiative: Policy Advocacy Toolkit for Medication-Assisted Treatment (MAT) for Drug Dependence, 2010. 